\title{
MENINGKATKAN ASPIRASI KARIER DI SEKOLAH MELALUI LAYANAN BIMBINGAN DAN KONSELING
}

\author{
Marimbun \\ IAIN Langsa
}

Email: marimbun.kauman@gmail.com

\begin{abstract}
ABSTRAK
Aspirasi karier merupakan cita- cita, harapan dan keinginan yang realistis untuk meraih prestasi yang cemerlang di masa depan. Setiap siswa pasti menginginkan karier yang cemerlang. Namun, kebanyakan siswa gagal dalam mempersiapkan kariernya. Fenomena yang terjadi di lapangan menggambarkan masih banyak siswa yang memiliki aspirasi karier yang rendah. Tujuan penelitian ini adalah menemukan layanan- layanan bimbingan dan konseling yang efektif dalam meningkatkan aspirasi karier. Jenis penelitian yang digunakan adalah studi kepustakaan. Teknik pengumpulan data menggunakan dokumentasi. Teknik analisis data adalah analisis isi yaitu memilih, membandingkan, menggabungkan berbagai referensi yang relevan. Guru Bimbingan Konseling atau konselor sebagai alternatif untuk memberikan berbagai layanan yang harus dilaksanakan dalam mengatasi berbagai hambatan karier. Layanan bimbingan dan konseling yang efektif dalam meningkatkan aspirasi karier adalah layanan informasi, bimbingan kelompok, konseling kelompok, dan layanan penguasaan konten.
\end{abstract}

\section{Kata Kunci: Aspirasi Karier, Layanan Bimbingan dan Konseling \\ IMPROVING CAREER ASPIRTIONS IN SCHOOLS THROUGH GUIDANCE AND COUNSELING SERVICES}

\begin{abstract}
Career aspirations are realistic goals, hopes and desires to achieve brilliant achievements in the future. Every student wants a brilliant career. However, most students fail to prepare for a career. The phenomenon that occurs in the field illustrates that there are still many students who have low career aspirations. The aim of this research is to find guidance and counseling services that are effective in increasing career aspirations. The type of research used is literature study. Data collection techniques using documentation. The data analysis technique is content analysis, namely selecting, comparing, combining various relevant references. guidance and counseling teachers or counselors as an alternative to provide various services that must be implemented in overcoming various career obstacles. Guidance and counseling services that are effective in increasing career aspirations are information services, group guidance, group counseling and content mastery services.
\end{abstract}

Keywords: Career Aspirations, Guidance and Counseling Services 


\section{PENDAHULUAN}

Aspirasi karier merupakan cita- cita, harapan dan keinginan yang realistis untuk meraih prestasi yang cemerlang di masa depan. Aspirasi karier sangat penting untuk diaplikasikan dalam pendidikan (Ramadhani, 2017).Aspirasi karier dipandang perlu untuk memotivasi siswa dalam pengembangan karier yang ada pada dirinya. Aspirasi karier menjadi salah satu faktor yang mempengaruhi potensi diri untuk mencapai kematangan karier. Aspirasi karier menggerakkan tindakan- tindakan yang positif yang membantu siswa memilih karier yang sesuai dengan potensinya (Widiastuti, 2017). Salah satu tugas perkembangan siswa sebagai remaja adalah memilih dan mempersiapkan karier di masa depan. Selain itu, aspirasi karier dibutuhkan pada siswa untuk motivasi internal dalam mencapai prestasi di sekolah (Hayati, 2017). Pemahaman diri, menentukan target, membuat keputusan, dan mempersiapkan diri untuk memasuki dunia kerja menjadi arah karier yang harus ditekuni. Perencanaan karier akan sumber memotivasi bagi siswa untuk mempersiapkan diri dalam menjalani kariernya (Latif et al., 2017)

Perencanaan karier harus disesuaikan dengan bakat, minat dan kemampuan. (Pambudi et al., 2020). Kesiapan untuk mengambil keputusan merupakan langkah awal dalam merencanakan kariernya (Rahman \& Moesarofah, 2020). Aspirasi karier merefleksikan keinginan atau ambisi untuk memperoleh pekerjaan di bidang yang diminati. Menurut Holland Aspirasi karier menjadikan siswa siap mengambil keputusan karier sesuai dengan minat

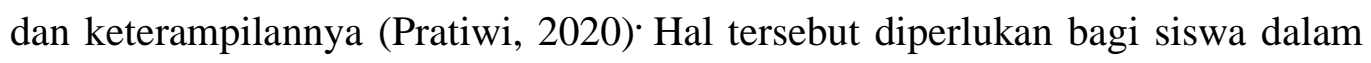
menentukan langkah yang tepat dalam memilih karier bagi masa depan dengan mempertimbangkan faktor- faktor yang ada pada diri, seperti gambaran diri, kelebihan yang dimiliki serta kekurangan dirinya (Pratiwi, 2020).Setiap siswa pasti menginginkan karier yang cemerlang. Namun, kebanyakan siswa gagal dalam mempersiapkan kariernya. (Adharsyah, 2019). Banyak dari siswa yang mengalami kesulitan mempersiapkan diri memilih kelanjutan studi atau memilih karier yang sesuai dengan dirinya (Fandini, hario \& Purwoko, 2018).

Fenomena yang terjadi di lapangan masih banyak siswa yang belum memiliki aspirasi karier yang baik. Oleh karena itu, dibutuhkan layanan dalam 
menangani siswa yang memiliki aspirasi karier rendah yang efektif (Hayati, 2017). Dampak yang ditimbulkan oleh aspirasi karier yang rendah mengakibatkan banyak siswa yang gagal dalam menempuh kariernya.Selain keterampilan, kurangnya informasi terkait dengan karier menjadi alasan bertambahnya pengangguran. (Franita, 2016). Badan Pusat Statistik (BPS) mendata pengangguran terbuka pada bulan Agustus 2019 dengan jumlah 7,05 juta orang, sementara pada bulan Agustus 2018 yang berjumlah 7 juta orang. Tingkat pengangguran terbuka (TPT) kebanyakan adalah lulusan Sekolah Menengah Kejuruan (SMK) sebesar 10,42\% pada bulan Agustus 2019. Sekolah Menengah Atas (SMA) berada pada peringkat yang kedua dengan persentase 7,92 \%, diploma I/II/III dengan persentase 5,99 \%, universitas dengan persentase 5,67 \%, Sekolah Menengah Pertama (SMP) dengan persentase 4,75\%, dan Sekolah Dasar dengan persentase 2,41 \%. (Citradi, 2019; Ulya, 2019)

\section{LANDASAN TEORI}

Hasil Penelitian Jalil (2020), menjelaskan bahwa tingkat pengangguran pada masa pandemi semakin meningkatkan. Badan Pusat Statistik (BPS) mencatat pada bulan Agustus 2020, pengangguran mengalami peningkatan sebesar 2, 67 juta orang, dari 5, $23 \%$ meningkat menjadi 7,07 \% (Putra, 2020). Selanjutnya, pada era revolusi industri 4.0, beberapa pekerjaan akan tertukar oleh beberapa pekerjaan yang baru. Bambang Satrio Lelono selaku Direktur Jenderal (Dirjen) Pembinaan, Pelatihan dan Produktivitas Kemenaker, menyampaikan bahwa, 57\% pekerjaan yang ada pada saat ini akan hilang pada tiga periode revolusi industri 4.0 sejak 2018 hingga 2030. Survei World Economic Forum tentang pekerjaan di masa depan diproyeksikan tumbuh sampai 33\% pada tahun 2022 (Adharsyah, 2019; Pambudi et al., 2020). Hasil survei dipahami perlunya pelayanan bimbingan dan konseling agar siswa mendapatkan layanan meningkatkan pemahaman diri (bakat, minat dan kemampuan), membuat perencanaan karier, mempunyai wawasan tentang dunia kerja, membuat keputusan dengan tepat, dan mengaktualisasikan potensinya sehingga mampu mewujudkan diri ke arah yang lebih bermakna (Pambudi et al., 2020). 
Pelayanan bimbingan dan konseling menjadi bagian yang integral dalam membimbing siswa mencapai perkembangan yang lebih optimal, Membimbing siswa mencapai tugas perkembangan karier yang sesuai dengan potensinya. Pelayanan bimbingan dan konselingsangat penting untuk meningkatkan aspirasi karier siswa di sekolah (Widiastuti, 2017).

\section{METODEPENELITIAN}

Jenis penelitian yang digunakan dalam penelitian ini adalah studi kepustakaan dengan mengumpulkan informasi- informasi yang berkaitan dengan masalah yang diteliti baik melalui buku, jurnal, laporan penelitian, tesis, tesis, dan sumber tertulis tercetak maupun elektronik (Harahap, 2014; Syaibani, 2012). Teknik pengumpulan data yang menggunakan dokumentasi mengumpulkan data dengan cara mencatat, mengelompokkan, dan mengorganisasikan secara sistematis (Arikunto, 2010). Teknik analisis data adalah analisis isi yaitu memilih, membandingkan, menggabungkan berbagai referensi yang relevan (Sabarguna, 2005). Analisis isi akan memperoleh konsep yang akan menjawab masalah penelitian (Neuendorf, 2016)

\section{PEMBAHASAN}

Bimbingan dan konseling di sekolah diupayakan mewujudkan perkembangan siswa dalam mengaktualisasikan potensi diri atau mencapai perkembangan siswa secara optimal. Tugas- tugas perkembangan siswa menjadi sasaran layanan BK yang harus dipahami oleh Guru BK atau konselor dalam pencapaian tugas perkembangan. Salah satu tugas perkembangan siswa adalah mengembangkan keterampilan yang sesuai kebutuhan dalam mempersiapkan karier, memahami bakat, minat, kemampuan dan arah kecenderungan karier (Tim Penyusun Panduan Bimbingan Dan Konseling Sekolah Dasar, Sekolah Menengah Pertama, Sekolah Menengah Atas, 2016)

Pencapaian karier diperlukan kematangan karier sebagai salah satu yang mempengaruhi aspirasi karier. Aspirasi karier terbentuk sejak post-natal sampai dewasa dan menjadi stabil saat memasuki usia dewasa. Siswa harus diarahkan agar mampu menilai kemampuan, minat dan nilai-nilai dalam mencapai perkembangan kariernya. (Widiastuti, 2017). Aspirasi karier sangat penting untuk ditingkatkan karena pencapaian karier siswa tergantung aspirasinya dalam 
menjalani jenjang karier yang diharapkannya. Selanjutnya, Badan Pusat Statistik (BPS) mengungkapkan tentang tingginya tingkat pengangguran siswa lulusan SMA/sederajat setiap tahun. Ketidakmampuan siswa menjadikan pendidikan menentukan arah kariernya. Hal ini dapat menunjukkan indikasi bahwa masih rendahnya aspirasi karier (Febriani et al., 2016).

Guru BK atau konselor sebagai alternatif untuk melaksanakan berbagai layanan yang dalam meningkatkan aspirasi karier sehingga siswa dibekali wawasan dan pengetahuan dalam proses menentukan arah kariernya. Guru BK atau konselor diharapkan memperkaya wawasan, pengetahuan dan keterampilan tentang karier untuk memfasilitasi siswa untuk menentukan arah karier yang sesuai dengan bakat dan minat siswa, Upaya- upaya perlu dilaksanakan dalam mengatasi berbagai hambatan karier diperlukannya keaktifan Guru BK atau konselor untuk memberikan kegiatan dalam rangka pengembangan diri melalui pelatihan, seminar, layanan dengan materi yang berkaitan dengan karier agar mampu meningkatkan aspirasi karier siswa di sekolah. (Widiastuti, 2017). Beberapa jenis layanan yang ada dalam BK direkomendasikan untuk dilaksanakan dalam meningkatkan aspirasi karier adalah layanan informasi, bimbingan kelompok, konseling kelompok dan layanan penguasaan konten.

Pertama adalah layanan informasi. Menurut Prayitno (2004, p. 259), layanan informasi merupakan upaya memberikan pemahaman kepada siswa tentang informasi- informasi yang dibutuhkan dalam menjalani proses kegiatan yang sesuai dengan rencana yang dikehendaki. Pelaksanaan layanan informasi ditujukan untuk membekali siswa untuk mendapatkan wawasan, pengetahuan, dan keterampilan yang diperoleh melalui Guru BK atau konselor (Marimbun, 2019). Selanjutnya, pelaksanaan layanan informasi mampu meningkatkan aspirasi karier siswa di sekolah. Hasil penelitian Ramadhani (2017), bahwa aspirasi karier bisa di tingkatkan melalui layanan informasi. Penelitian tersebut menjelaskan tentang tingkat aspirasi karier siswa sebelum mendapatkan layanan informasi dan setelah mendapatkan layanan informasi mengalami peningkatan. Selanjutnya, terlihat perbedaan aspirasi karier siswa sebelum dan sesudah melaksanakan layanan informasi dengan peningkatan yang signifikan. Layanan informasi mengarahkan siswa dalam memahami tentang dirinya serta berhasil 
meningkatkan aspirasi kariernya (Ramadhani, 2017). Senada dengan itu, kegiatan layanan informasi dengan menggunakan pendekatan discovery learning ternyata lebih efektif untuk meningkatkan aspirasi karier apabila dibandingkan dengan layanan informasi tanpa menerapkan pendekatan discovery learning (Ramadhani, 2016).

Siswa yang mempunyai perencanaan karier yang baik mempunyai kesiapan kerja yang lebih baik. Perencanaan karier yang baik tentu akan mempersiapkan segala sesuatu yang berhubungan dengan karier atau pekerjaan yang akan ditekuninya. Pekerjaan harus direncanakan dari awal agar bisa mempersiapkan diri untuk dapat menjalankannya dengan baik. (Latif et al., 2017). Selanjutnya, hasil penelitian Zulaidi (2017), menjelaskan bahwa layanan informasi terbukti efektif dalam meningkatkan perencanaan karier. Temuan penelitian menggambarkan perbedaan yang begitu signifikan tentang perencanaan karier siswa sebelum dan sesudah mengikuti layanan informasi. Penelitian Rahman \& Moesarofah (2020), menjelaskan tentang pengaruh layanan informasi media pohon karier terhadap perencanaan karier. maka dapat ditarik kesimpulan bahwa layanan informasi dengan teknik informasi media pohon karier pada siswa sangat berpengaruh. Siswa dapat meningkatkan perencanaan karier yang semula kategori rendah menjadi tinggi. (Rahman \& Moesarofah, 2020). Selanjutnya, layanan informasi karier berbasis life skills education terbukti efektif dalam meningkatkan perencanaan karier (Ekasari, 2015). Beberapa penelitian tersebut dapat disimpulkan bahwa layanan informasi sangat efektif dalam meningkatkan aspirasi karier

Kedua adalah layanan bimbingan kelompok. Romlah (2001, p. 13), bimbingan kelompok merupakan teknik bimbingan yang berupaya membimbing siswa untuk memperoleh perkembangan secara optimal yang sesuai bakat, minat, serta nilai-nilai yang dianutnya yang dilaksanakan dalam situasi kelompok.Layanan bimbingan kelompok dapat meningkatkan perencanaan karier, Pelaksanaan bimbingan kelompok membuat sejumlah siswa bersamasama melaksanakan dinamika kelompok untuk mendapatkan materi terkait dengan pokok bahasan (topik) yang mampu menambah pemahaman dan pengembangan keterampilan siswa, mengambil keputusan, serta mampu 
tindakan tertentu melalui dinamika kelompok (Afdal, 2011; Olfakhrina et al., 2014). Para siswa secara bersama- sama menyampaikan ide dan gagasannya tentang topik- topik penting, tujuan dari bimbingan kelompok yaitu dapat mengembangkan aspek pribadi dan memperoleh wawasan tentang topik yang dibahas. Bimbingan kelompok akan menambah keakraban antara anggota kelompok, kemampuan berkomunikasi, pemahaman yang mendalam terhadap topik pembahasan, mengembangkan sikap dan tindakan nyata untuk mencapai hal- hal yang diinginkan dalam kelompok (Olfakhrina et al., 2014).

Hasil penelitian Widowati (2016), menunjukkan bimbingan kelompok menggunakan media kartu bergambar dapat meningkatkan perencanaan karier, hasil penelitian menggambarkan terdapat perbedaan tingkat perencanaan karier sebelum dan sesudah dilaksanakan bimbingan kelompok. (Widowati, 2016). Selanjutnya,hasil penelitian Kusbandiami (2018), pengaruh teknik informasi dalam bimbingan kelompok terhadap perencanaan karier siswa. Maka dapat ditarik kesimpulan bahwa teknik informasi dalam bimbingan kelompok pada siswa sangat berpengaruh dalam bimbingan kelompok, responden dapat meningkatkan perencanaan karier siswa, yang semula dalam kategori rendah menjadi tinggi. Guru BK atau konselor mengupayakan peningkatan kematangan karier melalui layanan bimbingan kelompok dengan teknik Self-Management. Layanan bimbingan kelompok dengan teknik Self-Management bertujuan untuk mencapai kematangan karier siswa (Suwanto, 2018).

Ketiga adalah layanan konseling kelompok. Layanan konseling kelompok adalah salah satu layanan BK yang memampatkan dinamika kelompok untuk menyelesaikan masalah dan mengembangkan aspek pribadi (Prayitno, 2012). Beberapa hasil penelitian menjelaskan bahwa layanan konseling kelompok dengan menggunakan teknik Self Instruction terbukti efektif dalam meningkatkan aspirasi karier siswa. Penelitian Hayati (2017), bahwa konseling kelompok efektif dalam meningkatkan aspirasi karier siswa. Selanjutnya, hasil penelitian Ari (2019), bahwa layanan konseling kelompok dengan menggunakan teknik self-talk efektif dalam meningkatkan aspirasi karier siswa. Terdapat perbedaan tingkat keefektifan konseling kelompok teknik self-talk pada kelompok eksperimen dan kelompok kontrol untuk meningkatkan aspirasi siswa. 
Beberapa hasil penelitian tersebut dapat disimpulkan bahwa meningkatkan aspirasi karier dapat dilakukan melalui konseling kelompok.

Keempat adalah layanan penguasaan konten. Layanan penguasaan konten adalah proses bantuan yang diberikan kepada siswa agar menguasai kompetensi tertentu melalui kegiatan belajar. Dengan penguasaan konten, siswa diharapkan mempunyai kemampuan tertentu dalam memenuhi kebutuhannya. (Prayitno, 2012). Layanan Penguasaan konten bertujuan menambah keterampilan siswa untuk menguasai konten tertentu dengan terintegrasi. Penguasaan konten berguna untuk menambah keterampilan menguasai cara- cara tertentu, memenuhi kebutuhan, dan menguasai aspek- aspek masalahnya (Tohirin, 2008). Hasil penelitian Maulana \& Hildayani (2017), bahwa layanan penguasaan konten dapat meningkatkan kesiapan karier. Hasil pemberian layanan penguasaan konten membuktikan bahwa layanan penguasaan konten dapat meningkatkan kesiapan karier. Sementara siswa yang memiliki aspirasi karier yang baik dapat dipastikan mempunyai kesiapan karier yang baik. Upaya yang dapat dilakukan dalam meningkatkan aspirasi karier bisa melalui layanan penguasaan konten.

Aspirasi karier adalah salah satu tugas perkembangan siswa sebagai remaja yang harus menjadi sasaran layanan dalam pelaksanaan layanan BK di sekolah. Oleh karena itu, guru BK atau konselor diharapkan mampu memberikan berbagai jenis layanan BK yang sudah terbukti mampu meningkatkan aspirasi karier siswa di sekolah. Beberapa hasil penelitian terdahulu merekomendasikan kepada guru BK untuk dilaksanakan seperti layanan informasi, bimbingan kelompok, konseling kelompok dan penguasaan konten.

\section{KESIMPULAN}

Bimbingan dan konseling di sekolah diupayakan memfasilitasi perkembangan siswa untuk mengaktualisasikan potensi diri atau mencapai perkembangan siswa secara optimal. Tugas perkembangan siswa di sekolah menjadi sasaran layanan bimbingan dan konseling yang harus dipahami Guru BK atau konselor dalam pencapaian tugas perkembangan. Salah satu tugas perkembangan siswa adalah mengembangkan keterampilan yang sesuai kebutuhan dalam mempersiapkan karier, memahami kemampuan, bakat, minat, 
serta arah kecenderungan karier. Fakta di lapangan banyak siswa yang belum memiliki aspirasi karier yang baik. Guru BK atau konseling sebagai alternatif harus aktif memberikan berbagai layanan yang dapat meningkatkan aspirasi karier. Beberapa layanan yang efektif dalam meningkatkan aspirasi karier adalah layanan informasi, bimbingan kelompok dan konseling kelompok.

\section{SARAN}

Hasil penelitian ini menyarankan kepada guru- guru BK sebagai alternatif dalam meningkatkan aspirasi karier untuk memperkaya diri dengan pengetahuan dan keterampilan terkait dengan karier untuk memfasilitasi siswa untuk menentukan arah karier yang sesuai dengan bakat dan minat siswa, Upaya- upaya perlu dilaksanakan dalam mengatasi berbagai hambatan karier diperlukannya keaktifan Guru BK atau konselor untuk memberikan kegiatan dalam rangka pengembangan diri melalui layanan informasi, bimbingan kelompok, konseling kelompok dan penguasaan konten

Penelitian selanjutnya diharapkan mampu melakukan penelitian yang lebih mendalam berkaitan dengan meningkatkan aspirasi karier di seolah agar bisa diaplikasikan di dunia pendidikan.

\section{DAFTAR PUSTAKA}

Adharsyah, T. 2019. Jangan Salah Pilih Kuliah, Ini Pekerjaan yang Tren di Era 4.0. $C N B C$ Indonesia. https://www.cnbcindonesia.com/news/20190321182918-4-62193/jangansalah-pilih-kuliah-ini-pekerjaan-yang-tren-di-era-40

Afdal. 2011. Pelayanan Konseling untuk Mempersiapkan Siswa Mengikuti Ujian Nasional. Seminar Nasional Profesi Bimbingan Dan Konseling Di Padang.

Ari, U. 2019. Keefektifan Konseling Kelompok Teknik Self Talk untuk Meningkatkan Aspirasi dan Efikasi Karir Siswa Kelas XI TBSM SMK Al Falah Winong Pati. In Pascasarjana, Program Studi Bimbingan dan Konseling. Universitas Negeri Semarang.

Arikunto, S. 2010. Prosedur Penelitian Suatu pendekatan Praktek. Rineka Cipta.

Citradi, T. 2019. Miris! Tingkat Pengangguran Terbuka Lulusan SMK Paling Tinggi. $C N B C$ Indonesia. https://www.cnbcindonesia.com/news/20191105151115-4-112837/miristingkat-pengangguran-terbuka-lulusan-smk-paling-tinggi 
Ekasari, D. 2015. Pengembangan Model Layanan Informasi Karir Berbasis Life Skills Untuk Meningkatkan Pemahaman Dalam Perencanaan Karir Siswa Sma. Jurnal Bimbingan Konseling, 4(1).

Fandini, hario, S., \& Purwoko, B. 2018. Pengembangan Adobe Flash Sebagai Media Layanan Informasi Peminatan Studi Lanjut Sma Dan Sederajat Untuk Siswa Kelas IX SMPN 5 Sidoarjo. Jurnal BK Unesa, 8(1). https://jurnalmahasiswa.unesa.ac.id/index.php/jurnal- bkunesa/article/view/22735

Febriani, R. D., Yusuf, A. M., \& Iswari, M. 2016. Perbedaan Aspirasi Karier Siswa ditinjau dari Jenis Kelamin, Jurusan, dan Tingkat Pendidikan Orangtua serta Implikasinya terhadap Pelayanan Bimbingan dan Konseling. Konselor, 5(3), 160. https://doi.org/10.24036/02016536552-0-00

Franita, R. 2016. Analisa Pengangguran Di Indonesia. Jurnal Ilmu Pengetahuan Sosial, $\quad 1, \quad 88-93 . \quad$ http://jurnal.umtapsel.ac.id/index.php/nusantara/article/viewFile/97/97

Harahap, N. 2014. Penelitian Kepustakaan. Jurnal Iqra', 08(01), 68-73.

Hayati, I. N. 2017. Efektivitas Pelaksanaan Konseling Kelompok Teknik Self Instruction Untuk Meningkatkan Self-Efficacy Dan Aspirasi Karir Siswa SMA Negeri 7 Pekanbaru. Universitas Negeri Semarang.

Jalil, A., M, F., \& Kasnelly, S. 2020. Meningkatnya Angka Pengangguran Di Tengah Pandemi (Covid-19). 2(2), 45-60.

Kusbandiami, Dimas Ardika Miftah Farid, N. N. 2018. Pengaruh Teknik Informasi dalam Bimbingan Kelompok Terhadap Perencanaan Karier Siswa Kelas IX MTS Hasanuddin Sidoarjo. Jurnal HELPER, 35(2), 5-11.

Latif, A., Yusuf, A. M., \& Efendi, Z. M. 2017. Hubungan Perencanaan Karier dan Efikasi Diri dengan Kesipan Kerja Mahasiswa. Konselor, 6(1), 29. https://doi.org/10.24036/02017616535-0-00

Marimbun, M. 2019. Minat Membaca dan Implementasinya dalam Bimbingan dan Konseling. ENLIGHTEN: Jurnal Bimbingan Konseling Islam, 2(2), 7484. https://doi.org/10.32505/ENLIGHTEN.V2I2.1361

Maulana, R., \& Hidayati, N. W. 2017. Pemberian Layanan Penguasaan Konten Untuk Meningkatkan Kesiapan Karier Mahasiswa IKIP PGRI Pontianak. SOSIAL HORIZON: Jurnal Pendidikan Sosial, 4(2), 198-205.

Neuendorf, K. 2016. The Content Analysis Guidebook. Cleveland State University.

Olfakhrina, O., Syahniar, S., \& Nirwana, H. 2014. Pelaksanaan Layanan Bimbingan Kelompok untuk Menyiapkan Mental Siswa Menghadapi Ujian Nasional. Konselor, 3(2), 67. https://doi.org/10.24036/02014323231-0-00 
Pambudi, P. R., Muslihati, M., \& Lasan, B. B. 2020. Strategi untuk Membantu Meningkatkan Perencanaan Karier Siswa di Era Revolusi Industri 4.0. JKI (Jurnal Konseling Indonesia), 5(1), 28-33. https://doi.org/10.21067/jki.v5i1.4041

Pratiwi, G. R. \& Y. 2020. Self Regulated Learning Dan Konsep Diri Sebagai Prediktor Aspirasi Karier Pada Remaja. Jurnal Ilmiah Psyche, 14(1).

Prayitno. 2004. Seri layanan konseling. FIP UNP.

Prayitno. 2012. Jenis layanan dan kegiatan pendukung konseling. Padang: Program PPK FIP UNP.

Putra, D. A. 2020. Data BPS: Jumlah Pengangguran Bertambah 2,67 Juta Orang. Merdeka. Com. https://www.merdeka.com/uang/data-bps-jumlahpengangguran-bertambah-267-juta-orang.html

Rahman, A. J., \& Moesarofah. 2020. Pengaruh Layanan Informasi Menggunakan Media Pohon Karier Terhadap Perencanaan Karier Siswa Kelas XI IPA 1 MA Darul Ulum Waru Sidoarjo. 130-136.

Ramadhani, E. 2017. Efektivitas Layanan Informasi dalam Meningkatkan Aspirasi Karier Siswa. Wahana Didaktika, 15(2), 57-66.

Ramadhani, E. 2016. Efektivitas Layanan Informasi Menggunakan Pendekatan Discovery Learning dalam Meningkatkan Aspirasi Karier Siswa. Expanding of Counseling Services; World Views, Violence and Sexual Abuse Victims, 356.

Romlah, T. 2001. Teori dan praktek bimbingan dan konseling. Universitas Negeri Malang.

Sabarguna, B. S. 2005. Analisis Data pada Penelitian Kualitatif. UI Press.

Suwanto, I. 2018. Teknik Self Management Terhadap Kematangan Karir Siswa Smk Negeri 2 Singkawang. Jurnal Bimbingan Dan Konseling Indonesia, $3(1), 27-30$.

Syaibani, R. 2012. Studi Kepustakaan. http://repository.usu.ac.id/bitstream, diakses 14 Juni 2020

Tim Penyusun Panduan Bimbingan Dan Konseling Sekolah Dasar, Sekolah Menengah Pertama, Sekolah Menengah Atas, D. S. M. K. 2016. Panduan Operasional Penyelenggaraan Bimbingan Dan Konseling Sekolah Menengah Atas (SMA). http://eprints.uny.ac.id/54129/1/1. PANDUAN BK SD 2016\%2CDITJEN GTK revisi final 21 Des 2016.pdf

Tohirin. 2008. Bimbingan dan Konseling di Sekolah dan Madrasah (Berbasis Integrasi). PT Raja Grafindo Persada. 
Ulya, F. N. 2019. BPS: Pengangguran Meningkat, Lulusan SMK Mendominasi.KOMPAS.Com.

https://money.kompas.com/read/2019/11/05/155358926/bps-pengangguranmeningkat-lulusan-smk-mendominasi

Widiastuti, N. 2017. Aspirasi Karier Siswa SMA Berdasarkan Status Sosial Ekonomi dan Gender. Indonesian Journal of Educational Counseling, 1(2), 109-128. https://doi.org/10.30653/001.201712.9

Widowati, U. S. 2016. Pengembangan Media Kartu Bergambar Perencanaan Karier Pada Siswa Kelas VII Di SMP Negeri 1 Proppo Pamekasan. 53-59.

Zulaidi, R. Syahniar, Syukur, Y. 2017. Efektivitas Layanan Informasi dalam Meningkatkan Perencanaan Karier Siswa. The Responsibility of Counselor and Educator in Mellennium Era. http://repository.unp.ac.id/11226/1/RIZKA ZULAIDI-SYAHNIAR-YARMIS SYUKUR.pdf 